\title{
Analysing the Nepali Stock Market with Stochastic Models
}

\author{
Karan S. Thagunna, Rafal M. Lochowski
}

\begin{abstract}
In this article we analyse the behaviour of the Nepali stock market and movements of stock prices of selected companies using (i) Efficient Market Hypothesis (EMH) (ii) geometric Brownian motion model $(\mathrm{gBm})$ and (iii) Merton's jump-diffusion model. Using the daily returns of the NEPSE index and the daily returns of stock prices of selected companies we estimate the geometric Brownian motion model and Merton's jump-diffusion model. Further, we compare both models to identify the best fit for the Nepali stock market data.
\end{abstract}

Keywords: Black-Scholes model, Efficient Market Hypothesis, geometric Brownian motion, Merton's jump-diffusion Model, Variance Ratio Test

\section{Introduction}

Mathematicians and financial engineers developed many mathematical models used in stock price modelling and the geometric Brownian motion is one of the most commonly used. The assumptions leading to this model agree with rules imposed by the Efficient Market Hypothesis (EMH). These rules say that the future prices of a stock depend only on the present information about the stock. An efficient market is one in which the past information is freely accessible to all participants and the competition among the participants reflects the actual price, which depends also on the past information. The differing opinions about the intrinsic value cause the difference between the actual price and an equilibrium price. Due to many market participants the prices of an individual security change randomly about its equilibrium price (intrinsic value). Hence, the EMH states that the future price of an asset follows the random walk that cannot be determined by the current price or historical prices. A market is said to satisfy the weak-form of efficiency if the current prices of securities fully reflect all information contained in past prices, which means that studying the behaviours of historical prices cannot lead to abnormal retums. The implication of weak-form efficiency is that successive price changes are random and serially independent.
In the real world of financial markets, investors and financial analysts are generally more interested in the profit or loss from the investment in stock over a period of time i.e. the relative increase or decrease of the price rather than in the price self. Therefore, modelling behaviour of a stock price can be made through modelling its relative changes in time. Black and Scholes (1973) applied the Brownian motion process to model the evolution of stock prices in the continuous time $t \geq 0$. This model is known as the Black-Scholes (B-S) model or the geometric Brownian motion model ( $\mathrm{gBm}$ ). According to the geometric Brownian motion model, the logarithmic retums of a certain stock over successive, equal periods of time are independent and identically normally distributed. Thus, the logarithms of stock prices fom a random walk.

In contrast to that, many rese archers raised questions if the logarithms of stock prices follow the random walk process. Later, Lo and MacKinlay (1988) not only refuted the random walk hypothesis for U.S. stocks' weekly returns, but they also presented a powerful variance ratio test for the investigation of the applicability of the random walk hypothesis in other markets. This test is constructed upon the observation that for price movements following random walk, the variance of the logarithmic returns, $\log \left(\mathrm{P}_{\mathrm{t}} / \mathrm{P}_{\mathrm{t} \Delta t}\right)$, corresponding to the holding 
period $\Delta \mathrm{t}$ is $\mathrm{n}$ times greater than the variance of the logarithmic returns corresponding to the of monthly logarithmic returns, corresponding approximately to the holding period of four weeks, is approximately four times greater than the variance of weekly logarithmic returns. The test statistic of the Lo and MacKinlay variance ratio test is robust to many forms of heteroscedasticity and nonnormality (Lock, 2007). Chang and Ting (2000) applied the Lo and MacKinlay methodology to the weekly movements of the Taiwan composite valueweighted stock market index (Taiex) and concluded that these movements do not fit to a random walk.

So, though theoretically the geometric Brownian motion seems to be a good way to model future stock movements, in practice it shows some shortcomings, especially when it is used to model price movements over short periods of time. Merton (1976) was the first who added compound Poisson process of jumps to the Brownian motion Poisson process of jumps to the Brownian motion
process, in order to approximate the movements process, in order to approximate the movements
of logarithms of stock prices subject to occasional discontinuous breaks. In the Merton jump-diffusion model, changes in the asset price are a mixture of normal events that occur in continuous fashion and of rare events, which are modelled as jumps that occur sporadically.

In this article we aim to analyse the be behaviour of Nepali stock market and movements of daily stock prices of selected companies using (i) Efficient Market Hypothesis (ii) weak form of market efficiency (iii) the Black-Scholes model and (iv) Merton's jump diffusion model. We try to capture the weak stock market efficiency using he daily NEPSE index and then fitting the daily stock prices of selected companies to estimate the Black-Scholes and Merton's model. Furthermore we compare both models to identify the best fit for Nepali stock market data. The structure of the succeeding part of this article is as follows: in Section 1 we review the Nepali stock market and literature, which is followed by methodology in Section 2. In the methodology section we describe the mathematical forms and research hypothesis of all mentioned models, data acquisition and analysis tools. In Section 3 we present the results and analyse the outputs. Finally, in Section 4 we present the conclusions and implications of the research.
1. History of Nepali Stock Market and Literature Review

\subsection{History of Nepal Stock Exchange (NEPSE)}

The history of Nepal Stock Exchange (NEPSE) is shorter than the history of securities market in Nepal which begun in 1937 by floating the shares of Biratnagar Jute Mills Ltd. and Nepa Bank Ltd. The Security Exchange Centre Ltd. was established in 1976 and was converted into a stock exchange in 1993. NEPSE opened its trading floor for licensed members on 13th January 1994. Members of NEPSE are permitted to act as intermediaries in buying and selling governmen bonds and listed corporate securities. At present, there are 23 member brokers and 2 market makers. NEPSE started the automated trading system, NEPSE Automated Trading System (NATS), in 2007 which adopts the principle of order driven market. As of November 2012, the number of total listing in NEPSE is 220 with market capital of $\$ 3$ 674.64 million, which includes commercial banks, hydropower companies, insurance companies, hotels, financial companies. However the efficiency of Nepal stock market is under serious doubt since majority of corporate firms such as manufacturing and trading are under performing except banking and some service sector. The confidence of Nepal investors toward stock market is not persistent due to the uncertain political situation and immature financial sector.

\subsection{Literature Survey on Nepal Stock}

\section{Exchange}

Although there is an abundant academic literature on global stock market, especially in the develope countries, but one finds little literature on the Nepali stock market. Our review starts with the work of Gurung (2004). In his article he analysed the growth and performance of Nepali security market by using simple correlation analysis. His study revealed that the Nepali security returns are erratic and unsynchronized. Pradhan and Balampaki factors a fecting stock retre alo factors affecting stock returns and found that stock returns are positively correlated with the earning yield and size whereas negatively correlated with book-to-market ratio, cash flow yield and book-to- market equity. Joshi and K.C. (2005) performed the efficiency tests and calendar anomalies of Nepali to 2004. Using regression model with dummy calendar effect, they found the evidence of day-ofthe week effect but not the holiday effect, turn-of-the month and time-of-the-month effect. Furthermore they found the inefficient weak form with respect to the day-of-the-week anomaly but weakly efficient for others. Variance analysis was performed by G.C. (2008) using volatility models. He analysed the volatility of daily return of Nepali stocks from the period 2003-2009 using $\operatorname{GARCH}(1,1)$ model for the conditional heteroskedasticity. The study found the distribution of the daily return series for the Nepali stock market to be leptokurtic, non-normal and exhibiting significant time dependencies. The conditional volatility of the NEPSE return series was modelled using a random walk model, a non-linear $\operatorname{GARCH}(1,1)$ model and three asymmetric models: GJR model, $\operatorname{EGARCH}(1,1)$ and PARCH $(1,1)$. The study found that the NEPSE Index returns series exhibits stylized characteristics supported by empirical evidence in different studies, such as volatility clustering, time-varying conditional heteroskedasticity and leptokurtosis. Pradhan and K.C. (2010) tested the weak market efficiency and random walk hypothesis using the weekly stock prices of 26 companies over the period from July 2005 to July 2008 . They found no evidence of the weak market efficiency hypothesis. Further test of stock market efficiency has been done by Bhatta (2010) using the daily, weekly and monthly stock market returns. Applying the autocorrelation test and runs test author found that Nepali stock market does not show any sign of weak efficiency and returns follow no random walk process. G.C. (2010) continued the similar tests for the weak market efficiency of Nepali stock market using 1970 daily observations from 2003 to 2009. The study employed five different tests of a random walk: autocorrelation test, runs test, unit root tests (ADF, PP, and KPSS), variance ratio test and autoregressive conditional heteroskedasticity test. The results of the tests are in broad agreement, conclusively rejecting the presence of random walk in daily returns of the eight stock market indices. Kadaria (2011) analysed the market reaction of the investors through the qualitative data analysis with the sample size of 185 stock investors. He found that
Analysing the Nepali Stock Market with Stochastic Models the capital structure and average pricing method is the key factor that determines the stock pricing.

To our best knowledge, our study where we try to employ the continuous time market models for the Nepali stock market data is the first of its kind. We try to fit the data selected from the various industrial sectors into two stochastic processes so that we can capture the random effects and 'rare' jump effects. Furthermore, we compare both stochastic models to estimate the parameters and to analyse the value at risks $(\mathrm{VaR})$ at different confidence levels.

\section{Methodology and Data}

\subsection{Tests and Models}

Variance Ratio(VR) test: Testing EMH. The variance ratio for the period is defined as

$$
\operatorname{VR}(\mathrm{k})=\frac{\sigma^{2}(\mathrm{k})}{\sigma^{2}(1)^{\prime}}
$$

where]

$$
\begin{aligned}
& \quad \sigma^{2}(\mathrm{k})=\frac{1}{\mathrm{k}(\eta-1)(\mathrm{n} \cdot \mathrm{k}-\mathrm{k}+1)} \sum_{\mathrm{t}=\mathrm{k}}^{\mathrm{n} \cdot \mathrm{k}}\left(\mathrm{x}_{\mathrm{t}}-\mathrm{x}_{\mathrm{t}-\mathrm{k}}-\mathrm{k} \hat{\mu}\right)^{2} . \\
& \sigma^{2}(1)=\frac{\eta}{\mathrm{n} \cdot \mathrm{k}-1} \sum_{\mathrm{t}=1}^{\mathrm{n} \cdot \mathrm{l}}\left(\mathrm{x}_{\mathrm{t}}-\mathrm{x}_{\mathrm{t}-1}-\hat{\mu}\right)^{2} . \\
& \text { and } \hat{\mu}\left(\mathrm{x}_{\mathrm{n} \cdot \mathrm{k}}-\mathrm{x}_{0}\right) /(\mathrm{n} \cdot \mathrm{k}) .
\end{aligned}
$$

Here $\mathrm{x}_{\mathrm{n} . \mathrm{k}}$ and $\mathrm{x}_{0}$ are the last and the first observation of logarithm of a stock price or a stock index. Note that in the formula for $\sigma^{2}(\mathrm{k})$ one uses overlapping periods, which are correlated.

The Lo and MacKinlay (1988) variance ratio (VR) test for the random walk process can be performed under both homoskedastic and heteroskedastic specifications. The asymptotic variances of the variance ratio under homoskedastic

and heteroskedastic specification are:

$$
\phi(\mathrm{k})=\frac{2(2 \mathrm{k}-1)(\mathrm{K}-1)}{3 \mathrm{k}(\mathrm{n} \cdot \mathrm{k})}
$$

and, respectively, $\quad \phi^{*} \sum_{\mathrm{q}=1}^{\mathrm{k}-1}\left[\frac{2(\mathrm{k}-\mathrm{q})}{\mathrm{k}}\right]^{2} \cdot \frac{\hat{\delta}(\mathrm{q})}{\mathrm{n} \cdot \mathrm{k}^{\prime}}$

Where,

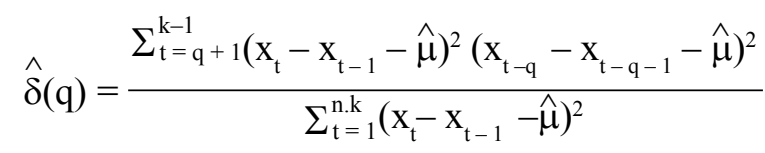


The $z$-statistics for the homoskedastic an heteroskedastic specifications are as follows:

$$
\mathrm{z}(\mathrm{k})=\frac{\mathrm{VR}(\mathrm{k})-1}{\sqrt{\phi(\mathrm{k})}}, \mathrm{z}(\mathrm{k})=\frac{\mathrm{VR}(\mathrm{k})-1}{\sqrt{\phi^{*}(\mathrm{k})}},
$$

and under the random walk null hypothesis they have for large $\mathrm{n}$ approximately standard normal distribution.

\section{The run test ${ }^{2}$ of randomness: a test for weak} efficiency. Widely used test for the weak-form efficiency of a market is the 'run test'; it does not require the assumption that logarithmic returns are normally distributed. A 'run' is defined as "a succession of identical symbols which are followed or preceded by different symbols or no symbol at all". The number of runs is computed as a sequence of the price changes of the same sign (such as; $++,--, 00)$. When the expected number of runs is significantly different from the observed number of runs, the test rejects the null hypothesis that the daily returns are random.

The expected number of runs is represented by:

$$
\mu(\mathrm{R})=\frac{\mathrm{n}+2 \mathrm{n}_{1} \mathrm{n}_{2}}{\mathrm{n}}
$$

where $\mathrm{n}$ is the total number of observations, $\mathrm{n}$ $\mathrm{n}_{2}$ respectively represent the observations above and below the sample mean(median) and R is the observed number of runs. The standard deviation of $\mathrm{R}$ is:

$$
\sigma(R)=\left[\frac{2 n_{1} n_{2}\left(2 n_{1} n_{2}-n\right)}{n^{2}(n-1)}\right] .
$$

The $\mathrm{z}$-test statistic is expressed as

$$
\mathrm{z}(\mathrm{R})=\frac{\mathrm{R}-\mu(\mathrm{R})}{\sigma(\mathrm{R})}
$$

and under the null hypothesis it has for large ns approximately standard normal distribution. The null hypothesis for the runs test means temporal independence in the observations, which is a weak form of efficiency.

Stochastic models. Cuthbertson (1996, Ch. 5) and Wilmott et al. (1997, Ch. 2) state that the efficient market hypothesis $(\mathrm{EMH})$ is one possible reason for the random behaviour of the asset prices. Depending on the appearance of the so called "normal" ${ }^{2}$ Wald, A. and Wolfowitz, J. (1943) An exact test for randomnes the non-parametric case based on serial correlation. An and "rare" events, there are two basic blocks in modelling the continuous-time asset prices. Neftci the "normal" and the "rare" behaviour concerns the size of the events and their probability to occur. As the time interval between consecutive observations, $\Delta t$, gets smaller, the size of "normal" events also gets smaller and it becomes unimportant as $\Delta \mathrm{t} \downarrow 0$ Even in a short time interval there is always a nonzero probability that some non-noticeable news will arrive. In contrast to a "normal" event, when a "rare" event (or shock) occurs the value of random variable can change significantly over a short period of time. An example of a "rare" even is a market crash, such as the one that occurred in 1987. In other wo "rare" event moves to zero as $\Delta t \downarrow 0$, its size does not shrink

The geometric Brownian motion process. If the market is dominated by "normal" events, then Brownian motion process can be used. This is continuous-time stochastic process, where extremes occur very rarely, according to the tail probabilities of the normal distribution. One has the following stochastic differential equation for the asset price, proposed by Black and Scholes (1973):

$$
d S_{t}=v S_{t} d t+\sigma_{t} S_{t} d W_{t}
$$

Here $\mathrm{S}_{\mathrm{t}} v, \sigma, \mathrm{W}_{\mathrm{t}}$ denote the current price of the asset the constant rate of return or the drift, the volatility and the Brownian ${ }^{3}$ or Wiener process. The asset price in (1) follows the geometric Brownian motio process and equation (1) is called a stochastic differential equation, because the asset price $S_{1}$ is defined implicitly, by describing its changes through time with random (stochastic) effects. Since this process has a continuous sample paths, it does not exhibit discontinuities or jumps, i.e. no "rare" events occur.

An explicit solution of (1) is given by the geometric Brownian motion process:

$\mathrm{S}_{\mathrm{t}}=\mathrm{S}_{0} \exp \left(\left(\mathrm{v}-\frac{\sigma^{2}}{2}\right) \mathrm{t}+\sigma \mathrm{W}_{\mathrm{t}}\right)=\mathrm{S}_{0} \exp \left(\mu \mathrm{t}+\sigma \mathrm{W}_{\mathrm{t}}\right)$, where $\mu=v \sigma^{2} / 2$. The daily logarithmic returns of the stock are

a Brownian motion process $\mathrm{W}_{\mathfrak{t}}, \mathrm{t} \geq 0$, is a continuous stochastic process with the following properties (i) it starts at zero, i.e. $\mathrm{W}_{\mathrm{o}} \equiv 0$; (ii) it has independent increments; (iii) for every $\mathrm{t}>\mathrm{s}>$
$0, \mathrm{~W}-\mathrm{W}$ has normal distribution $\mathrm{N}(0, \mathrm{t}-\mathrm{s})$ $\ln \frac{S_{t}}{S_{t}-1}=\operatorname{In} S_{t}-\operatorname{In} S_{t}-1=\mu+\sigma\left(W_{t}-W_{t-1}\right) \sim N\left(\mu, \sigma^{2}\right)$ i.e. In $\mathrm{S}_{\mathrm{t}}-$ In $\mathrm{S}_{\mathrm{t}-1}$ has normal distribution with meanand variance $\sigma^{2}$. We can generalize this for any $\Delta \mathrm{t}>0$ and have

In $\mathrm{S}_{\mathrm{t}}-\operatorname{In} \mathrm{S}_{\mathrm{t}-\Delta \mathrm{t}}=\mu . \Delta \mathrm{t}+\sigma\left(\mathrm{W}_{\mathrm{t}}-\mathrm{W}_{\mathrm{t}-\Delta \mathrm{t}}\right) \sim \mathrm{N}\left(\mu . \Delta \mathrm{t}, \sigma^{2} \Delta \mathrm{t}\right)$

In particular, $X_{t}=\ln S_{t}-\ln S_{0}$ is a Brownian motion process with drift, $X_{t}=\mu t+\sigma W_{t}$ for $t \geq 0$ and for fixed $t, X$ has normal distribution with the density

$$
\mathrm{fx}_{\mathrm{t}}(\mathrm{x})=\frac{1}{\sigma \sqrt{2 \pi \cdot t}} \exp \left(-\frac{(\mathrm{x}-\pi \cdot \mathrm{t})^{2}}{2 \sigma^{2} \mathrm{t}}\right)
$$

Merton's jump-diffusion process. Merton (1976) was one of the first, who added jumps to the geometric Brownian motion process, in order to approximate the movements of stock prices subject to occasional discontinuous breaks. In the jumpdiffusion model, changes in the logarithm of the asset price are a mixture of normal events that occur in continuous fashion and of rare events, which are modelled as jumps that occur sporadically, according to a Poisson process $N(t), t \geq 0$. The probability of a jump that occurs during a time interval of small length $h>0$ reads as

$\mathrm{P}\{$ the event occurs in $(\mathrm{t} ; \mathrm{t}+\mathrm{h})\}=\lambda \mathrm{h}+\mathrm{o}(\mathrm{h})$

$\mathrm{P}\{$ the event does not occur in $(\mathrm{t} ; \mathrm{t}+\mathrm{h})\}=1-\lambda \mathrm{h}+\mathrm{o}(\mathrm{h})$,

where $\lambda>0$ is the intensity of the jump process, i.e. the number of jumps per unit of time, which do not depend on the information set available at time $\mathrm{t}$, and $\mathrm{o}(\mathrm{h}) / \mathrm{h} \downarrow 0$ as $\mathrm{h} \downarrow 0$. For fixed $\mathrm{t} \geq 0, \mathrm{~N}(\mathrm{t})$ has Poisson distribution with parameter $\lambda$. t. This means that the probability that till time $t>0$ there were exactly $\mathrm{k}$ jumps reads as

$$
\mathrm{P}(\mathrm{N}(\mathrm{t})=\mathrm{k})=\frac{(\lambda \cdot \mathrm{t})^{\mathrm{k}}}{\mathrm{k} !} \mathrm{e}^{-\lambda . \mathrm{t}} .
$$

In Merton's jump-diffusion model the stock price evolution is given by the process

$$
\mathrm{S}_{\mathrm{t}}=\mathrm{S}_{0} \exp \left(\mu . \mathrm{t}+\sigma \mathrm{W}_{\mathrm{t}}+\sum_{j=1}^{N(t)} \mathrm{Y}_{j}\right) . \quad \text { (2) }
$$

Here $Y_{i}, j=1,2, \ldots$, are i.i.d. normal random variables. Processes $W, N(t), t \geq 0$, and the variables $\mathrm{Y}_{\mathrm{j}}, \mathrm{j}=1,2, \ldots$, are independent.

The jump-diffusion model (2) undoubtedly captures phenomena that are missing in the Black-Scholes
Analysing the Nepali Stock Market with Stochastic Models model (1), yet, it is rarely used in practice. There are two main reasons for this: difficulty in paramete estimation, and no possibility of perfect hedging (Wilmott (1999), Ch. 26). The distribution of returns is leptokurtic. The jump-diffusion model gives higher values than the Black-Sholes model for deep out-of-the-money and in-the-money options, especially when the time to maturity is short.

In Merton's jump diffusion model the logarithmic security return reads as:

$$
\operatorname{In} \frac{S_{t}}{S_{t-\Delta t}}=\mu . \Delta t+\sigma\left(w_{t}-w_{t-\Delta t}\right)+\sum_{j=N(t-\Delta t)+1}^{N(t)} Y_{j}
$$

and, assuming that $\mathrm{Yj} \sim \mathrm{N}\left(\mathrm{m}, \mathrm{s}^{2}\right)$, the probability density function (pdf) of $\mathrm{X}_{\mathrm{t}}=\ln \mathrm{S}_{\mathrm{t}}-\ln \mathrm{S}_{0}$ reads as

$\mathrm{fx}_{\mathrm{t}}(\mathrm{x})=\mathrm{e}^{-\lambda . t} \sum_{\mathrm{k}=0}^{\infty} \frac{(\lambda \cdot \mathrm{t})^{\mathrm{k}}}{\mathrm{k} !} \frac{1}{\sqrt{2 \pi\left(\sigma^{2} \mathrm{t}+\mathrm{k} \cdot \mathrm{s}^{2}\right)}} \exp \left(\frac{(\mathrm{x}-\mu \cdot \mathrm{t}-\mathrm{k} \cdot \mathrm{m})^{2}}{2\left(\sigma^{2} \mathrm{t}+\mathrm{k} \cdot \mathrm{s}^{2}\right)}\right)$

Three month VaR measure. The VaR (value at risk) is a principal tool in risk measuring adopte after the Basel Committee recommendation. VaR measures the worst expected loss under normal market conditions over the specified time period at a given confidence level. The big advantage of the classical Black-Scholes and Merton's model is the independence of logarithmic returns in the nonoverlapping holding periods. For both models we define the three month loss function for the VaR measure as:

$$
\mathrm{L}=\mathrm{S}_{0}-\mathrm{S}_{\Delta \mathrm{t}},
$$

where $\Delta \mathrm{t}$ corresponds to the total number of trading days between moment 0 and three months later.

Remark: In Nepal, due to 53 public holidays including a 17 days long festival in OctoberNovember, this period may vary, depending on the starting moment 0 . For example, for the momen 0 being July $16^{\text {th }}, 2012$, the three month holding period would correspond to $\Delta t=43$ trading days, while for the moment 0 being August $30^{\text {th }}$, 2012, the three month holding period would correspond to $\Delta t=53$ trading days

The $95 \% \mathrm{VaR}, \mathrm{VaR}_{95 \%}(\mathrm{~L})$ is defined as

$\operatorname{VaR}_{95 \%}(\mathrm{~L})=\inf \{l: \mathrm{P}(\mathrm{L}>1) \leq 5 \%\}$.

Defining the three month logarithmic return, 
$\mathrm{r}_{3 \mathrm{~m}}=\ln \left(\mathrm{S}_{\Delta \mathrm{t}} / \mathrm{S}_{0}\right)$, we obtain $\mathrm{L}=\mathrm{S}_{0}\left(1-\exp \left(\mathrm{r}_{3 \mathrm{~m}}\right)\right)$ and $\operatorname{VaR}_{95 \%}(L)=\inf \left\{l: \mathrm{P}\left(\mathrm{S}_{0}\left(1-\mathrm{e}^{\mathrm{r}_{3 \mathrm{~m}}}\right)>1\right) \leq 5 \%\right\}$

$\mathrm{VaR}_{95 \%}(\mathrm{~L})=\left(1-\exp \left(\sup \left\{\mathrm{x}: \mathrm{P}\left(\mathrm{r}_{3 \mathrm{~m}}<\mathrm{x}\right) \leq 5 \%\right\}\right)\right) \mathrm{S}_{0}$

In both (B-S and Merton's) models logarithmic returns have continuous distribution, hence we get that $\sup \square\{\mathrm{x}: \mathrm{P}(\mathrm{r}-3 \mathrm{~m}<\mathrm{x}) \leq 5 \%\}$ corresponds to $5 \%$ quantile of the three month logarithmic return:

$\sup \left\{x: P\left(r_{3 m}<x\right) \leq 5 \%\right\}=\inf \left\{x: P\left(r_{3 m}<x\right) \geq 5 \%\right\}=x_{3 m, 5 \%}$.

Hence

$\operatorname{VaR}_{0.95}(\mathrm{~L})=\left(1-\mathrm{e}^{\mathrm{x}_{3,3,5 \%}}\right) \mathrm{S}_{0}$.

\subsection{Data}

NEPSE experienced unusual fluctuations in the year 2012, which was a highly turbulent period for Nepali investors, the stock prices behaved with stochastic volatility as the political and economic indicators of the country worsened. The highly volatile sector was the banking sector with net annual spread of $117 \%$ due to stagnant investment opportunities in the development programs and real estate property sector crash. Finance sector has shown least fluctuation with net annual spread of $8.34 \%$. In Figure 1, the overall NEPSE index indicates the turbulence with positive trend.

In this article we used daily quotations of the NEPSE index and daily closing prices of six different companies in the year 2012 to estimate the B-S and the Merton's model. To capture the better comparison between these two models we choose the best performing and highly trusted companies from the different sectors of economy: NABIL (banking), ZENITH (finance), SOALTEE (hotel), CHILIME (hydropower), GURAS (insurance) and UNILIVER (manufacturing).

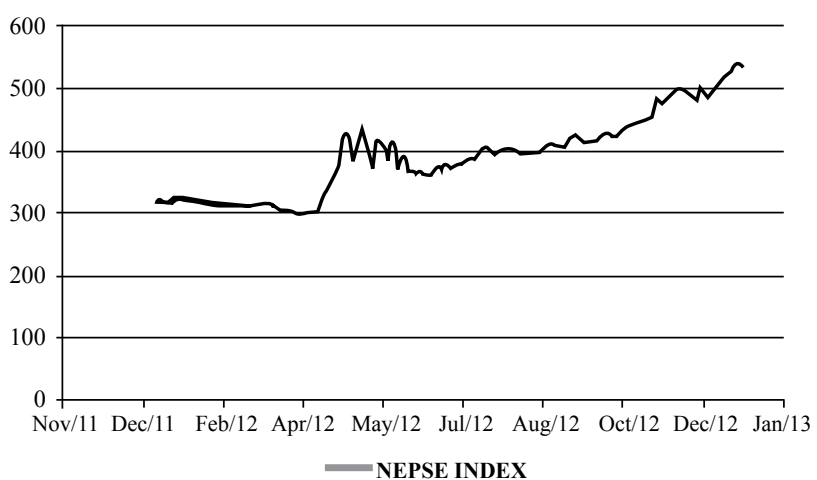

Figure 1. (NEPSE Index in the year 2012)

\section{Results and Analysis}

\subsection{Results of the VR test}

We employed vrtest package of $\mathrm{R}$ software to obtain the results of Lo-MacKinlay VR test for the intervals $\mathrm{k}=2,7,14,30$ trading days. The results of VR test are presented in Table 1. Furthermore, the variance ratio and $95 \%$ confidence band plots are shown in Figure 2

Using NEPSE index as a default price, the VR tes suggest that it follows random walk process since all $\mathrm{p}$-values have relatively high values for all holding periods. The confidence intervals also justify the results of the test except for $\mathrm{k}=2$. For $\mathrm{k}=2$ the tes statistics (z) lies beyond the confidence limit, which suggests the non-random walk process. Stock prices of the banking, hydropower and financial companies follow the random walk process of null hypocs $(p>0.05)$ when in stocks do not follow random process for the shorter
holding periods $(\mathrm{k}=2,7)$. Furthermore, for the manufacturing company stock prices the random walk hypothesis is rejected for all holding period at the $5 \%$ significance. The variance ratio with 95\% band plot in Figure-2 substantiates this result. For the holding period $\mathrm{k}=2$ the variance ravio Feyou the confdence band for the majoily of beyond the confidence band for the majority of the stocks, whereas the variance ratio statistics fo manufacturing company completely falls outside the band. Hence we conclude that the VR tes supports the random walk hypothesis except for small holding periods $(\mathrm{k}=2,7)$.

\section{Table 1. (VR test for the selected stocks' returns)}

\begin{tabular}{lllllll}
\hline \multicolumn{2}{c}{ Z-Stat } & & p-value & VR(k) & \multicolumn{2}{c}{ Confidence Interval } \\
\hline \multicolumn{2}{c}{$\mathrm{z}$} & $\mathrm{z}^{*}$ & & & $2.5 \%$ & $97.5 \%$ \\
\hline NEPSE Index & & & & & \\
\hline $\mathrm{k}=2$ & 2.3348 & 1.0867 & 0.290 & 1.1530 & 1.8927 & 1.8849 \\
\hline $\mathrm{k}=7$ & -0.4577 & -0.2363 & 0.828 & 0.9183 & -1.4802 & 1.9761 \\
\hline $\mathrm{k}=14$ & 0.7190 & 0.3831 & 0.682 & 1.1926 & -1.3425 & 2.2952 \\
\hline $\mathrm{k}=30$ & 0.0580 & 0.0330 & 0.942 & 1.0234 & -1.1642 & 2.1550 \\
\hline Manufacturing & & & & & \\
\hline $\mathrm{k}=2$ & 7.1864 & 4.4771 & $<0.05$ & 1.4924 & -1.8668 & 1.8232 \\
\hline $\mathrm{k}=7$ & 9.4442 & 6.3761 & $<0.05$ & 2.7637 & -1.6640 & 2.1913 \\
\hline $\mathrm{k}=14$ & 7.3418 & 5.4237 & $<0.05$ & 3.0566 & -1.6100 & 2.1394 \\
\hline $\mathrm{k}=30$ & 3.1961 & 2.6488 & $<0.05$ & 2.3504 & -1.4806 & 1.8500 \\
\hline Banking & & & & & & \\
\hline $\mathrm{k}=2$ & 2.6879 & 1.7741 & 0.062 & 1.1842 & -1.9474 & 1.7073 \\
\hline $\mathrm{k}=7$ & -0.1028 & -0.0714 & 0.974 & 0.9808 & -1.6014 & 2.0068 \\
\hline $\mathrm{k}=14$ & 0.7221 & 0.5141 & 0.620 & 1.2022 & -1.4682 & 2.4010 \\
\hline $\mathrm{k}=30$ & -0.0902 & -0.0666 & 0.998 & 0.9619 & -1.2747 & 2.3929 \\
\hline
\end{tabular}

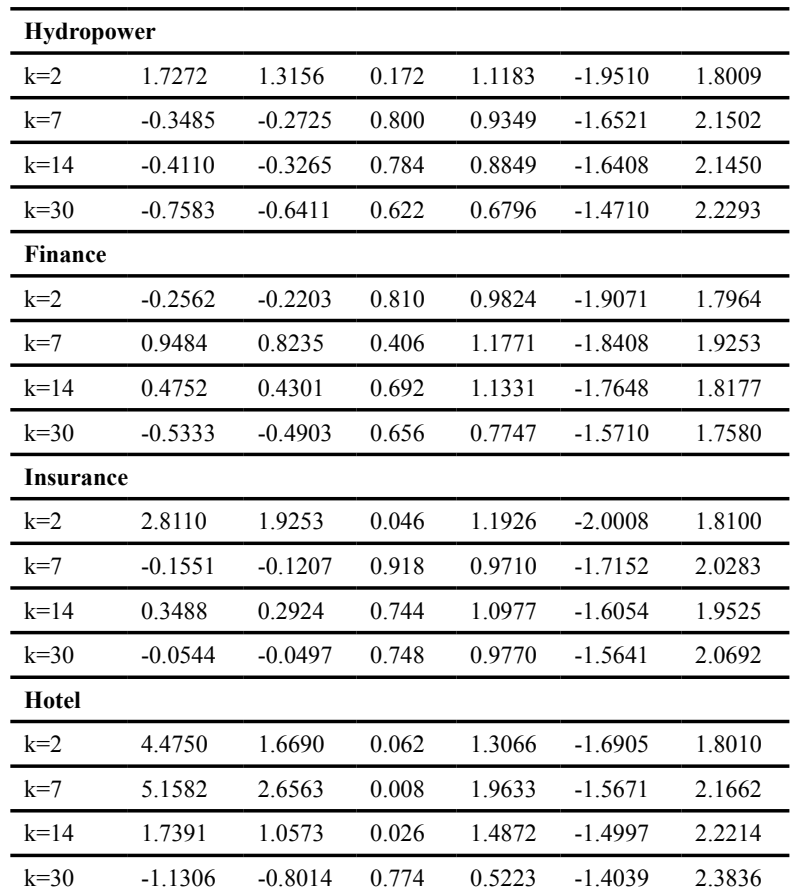

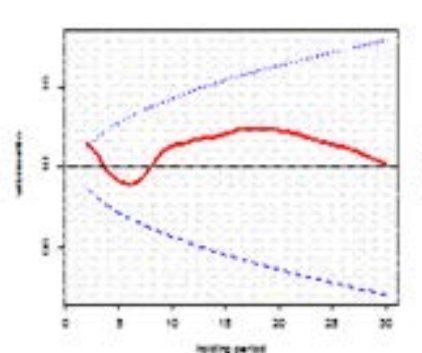

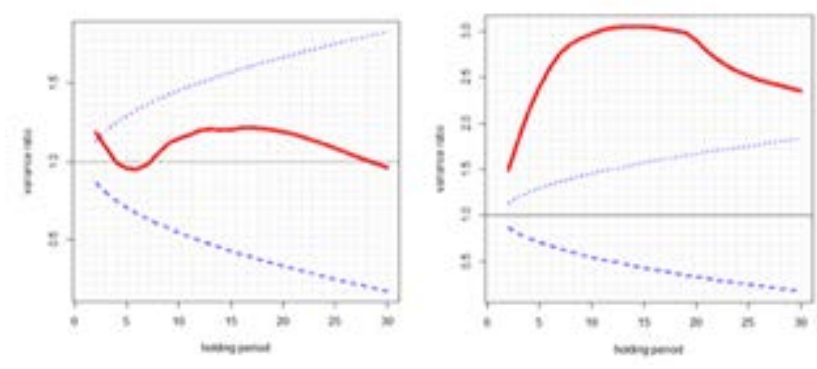

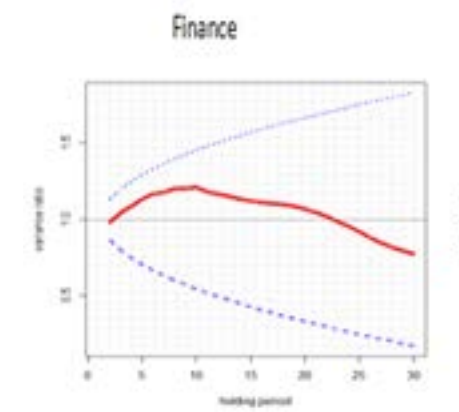
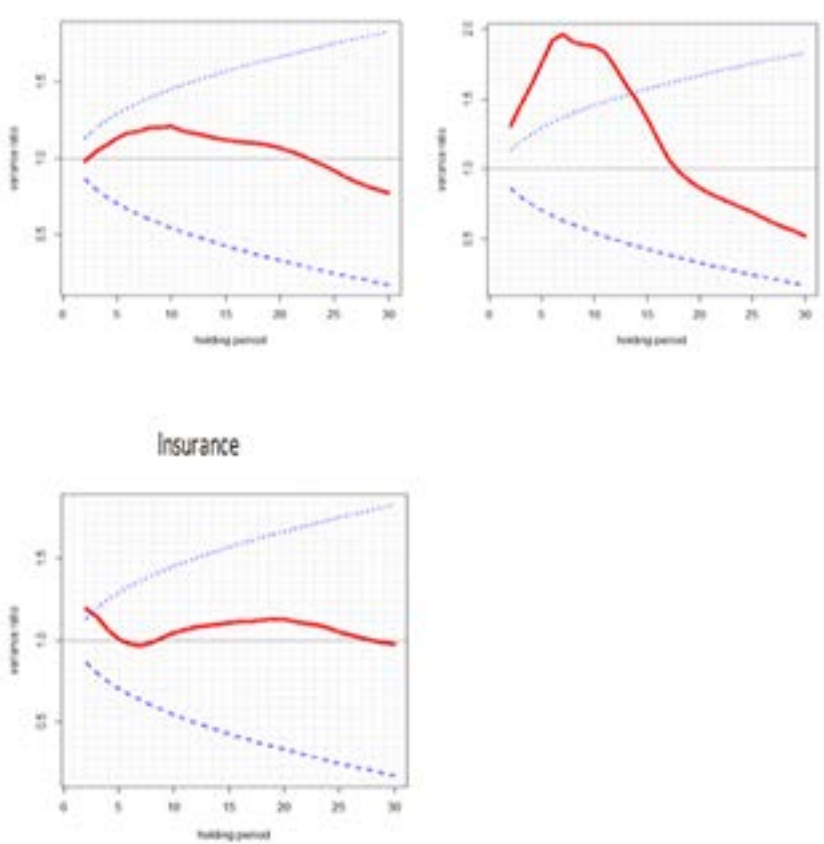

Figure 2. (Variance ratios and $95 \%$ confidence band)

\subsection{Results of the run test.}

We applied a non-parametric runs test for the weak form of randomness for daily, weekly and biweekly returns of NEPSE index and the six companies. The null hypothesis of the runs test is a weak form of market efficiency without assuming normality of the observations. The outputs of the test are shown in Tables 2, 3 and 4.

Table 2. (Results of the run tests for daily returns)

\begin{tabular}{|c|c|c|c|c|c|c|c|}
\hline & index & manuf & bank & hydro & finance & $\begin{array}{l}\begin{array}{l}\text { insur } \\
\text { ance }\end{array} \\
\text { ansur }\end{array}$ & hotel \\
\hline Test Value & .0005 & .0009 & .0000 & .0013 & .0000 & .0000 & .0005 \\
\hline $\begin{array}{c}\text { Casess } \\
\text { Test Vulue }\end{array}$ & 106 & 106 & 95 & 106 & 86 & 91 & 106 \\
\hline $\begin{array}{l}\text { anses }>\text { Test } \\
\text { Test Value }\end{array}$ & 107 & 107 & 118 & 107 & 127 & 122 & 107 \\
\hline $\begin{array}{l}\text { Expected } \\
\text { Runs }\end{array}$ & 107.5 & 107.5 & 106.26 & 107.5 & 103.55 & 105.24 & 107.5 \\
\hline $\begin{array}{l}\text { Number of } \\
\text { Runs }\end{array}$ & 86 & 18 & 104 & 87 & 85 & 103 & 42 \\
\hline z & -2.953 & -12.294 & -.314 & -2.816 & -2.647 & -315 & -8.997 \\
\hline 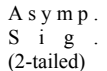 & .003 & .000 & .754 & .005 & .008 & .75 & .000 \\
\hline
\end{tabular}


Analysing the Nepali Stock Market with Stochastic Models

Table 3. (Results of the run tests for weekly returns)

\begin{tabular}{|c|c|c|c|c|c|c|c|}
\hline & index & manuf & bank & hydro & finance & $\overline{\text { insurance }}$ & hotel \\
\hline est Value & . 0019 & .0047 & .0076 & .0107 & . 0000 & . 0095 & .0080 \\
\hline $\begin{array}{l}\text { Cases } \\
\text { Value }\end{array}$ & 21 & 21 & 21 & 21 & 18 & 21 & 21 \\
\hline $\begin{array}{l}\begin{array}{l}\text { aless } \\
\text { Value }\end{array} \\
\text { Vest }\end{array}$ & 21 & 21 & 21 & 21 & 24 & 21 & 21 \\
\hline Expected Runs & 22 & 22 & 22 & 22 & 21.6 & 22 & 22 \\
\hline $\begin{array}{l}\begin{array}{l}\text { Number of } \\
\text { Runs }\end{array} \\
\text { of }\end{array}$ & 22 & 14 & 21 & 19 & 23 & 21 & 18 \\
\hline$z$ & .000 & -2.343 & -.156 & -.781 & .296 & -.156 & -1.094 \\
\hline $\begin{array}{l}\text { Asymp. } \\
\text { (-2-ailedic) }\end{array}$ & 1.000 & .019 & .876 & .435 & .767 & .876 & .274 \\
\hline
\end{tabular}

Table 4. (Results of the run tests for biweekly returns)

\begin{tabular}{|c|c|c|c|c|c|c|c|}
\hline & index & manuf & bank & hydro & finance & insurance & hotel \\
\hline Test Value & .0124 & .0095 & .0161 & .0306 & .0000 & . 0370 & .0186 \\
\hline $\begin{array}{l}\text { Cases }<\text { Test } \\
\text { Value }\end{array}$ & 10 & 10 & 10 & 10 & 9 & 10 & 10 \\
\hline $\begin{array}{l}\text { Cases }>=\text { Test } \\
\text { Value }\end{array}$ & 11 & 11 & 11 & 11 & 12 & 11 & 11 \\
\hline $\begin{array}{l}\text { Expected } \\
\text { Runs }\end{array}$ & 11.48 & 11.48 & 11.48 & 11.48 & 11.29 & 11.48 & 11.48 \\
\hline $\begin{array}{ll}\begin{array}{l}\text { Number } \\
\text { Runs }\end{array} \\
\text { Rof }\end{array}$ & 11 & 10 & 9 & 7 & 15 & 5 & 13 \\
\hline z & .000 & .438 & -.887 & -1.785 & 1.471 & -2.682 & . 460 \\
\hline $\begin{array}{l}\text { Asymp. Sig. } \\
(2 \text {-tailed) }\end{array}$ & 1.000 & .661 & .375 & .074 & .141 & .007 & .646 \\
\hline
\end{tabular}

The runs test results show that the observed numbers of runs for longer period are close to the expected ones for all data $(p>0.05)$ (except for manufacturing company for weekly returns and insurance company for biweekly returns). Hence reject the hypothesis of the weak form of efficiency in the NEPSE returns. Based on these outputs it can be said that Nepalese Stock market is a weakly efficient market. This goes along the findings of the previous subsection, where the VR rejected the random walk hypothesis for small holding periods $(\mathrm{k}=2,7)$ but did not reject it for longer periods.

\subsection{Results on the geometric Brownian motion}

\section{and Merton's jump-diffusion model.}

To estimate the parameters $\mu, \sigma, m, s$ and $\mathrm{p}_{0}$ for $\Delta \mathrm{t}=1$ day we will utilize the maximum likelihood approach. Let $\mathrm{r}_{1}, \mathrm{r}_{2}, \ldots, \mathrm{r}_{\mathrm{n}}$ be consecutive observations of daily logarithmic returns of an asset and $\hat{\mu}_{\mathrm{M}}, \hat{\sigma}_{\mathrm{M}}, \hat{m}_{\mathrm{M}}, \hat{\mathrm{s}}_{\mathrm{M}}, \hat{p}_{0}, \mathrm{M}$ be maximum likelihood estimators of $\mu, \sigma, m, s$ and $\mathrm{p}_{0}=\mathrm{e}^{-\lambda}$ for $\Delta \mathrm{t}=1$ in the jump-diffusion model. Using the approximation $p_{3}=1-p_{0}-p_{1}-p_{2} p_{k}=0$ for $\mathrm{k} \geq 4$, we have

$\left(\hat{\mu}_{\mathrm{M}}, \hat{\sigma}_{\mathrm{M}}, \hat{m}_{\mathrm{M}}, \hat{\mathrm{s}}_{\mathrm{M}}, \hat{p}_{0^{\prime} \mathrm{M}}\right)=\arg \max _{\mu, \sigma, m, s, p_{0}} \prod_{t=1}^{n} \sum_{\mathrm{j}=0}^{\infty} \mathrm{p}_{\mathrm{j}}\left(\frac{\exp \left(-\frac{\left(\mathrm{r}_{1}-\mu-\mathrm{j}-\mathrm{m}\right)^{2}}{2\left(\sigma^{2}+\mathrm{j} . \mathrm{s}^{2}\right)}\right)}{\sqrt{2 \pi} \sqrt{\sigma^{2}+\mathrm{j} . \mathrm{s}^{2}}}\right)$

In Table 6 we present the obtained maximum likelihood estimates $\left(\hat{\mu}_{\mathrm{M}}, \hat{\sigma}_{\mathrm{w}}, \hat{m}_{\mathrm{M}}, \hat{\mathrm{s}}_{\mathrm{M}}, \hat{p}_{0, \mathrm{M}}\right)$ for NEPSE index and six assets considered. The estimation was based on the data from the period $15^{\text {th }}$ of January $2012-30^{\text {th }}$ of August 2012. In the maximum likelihood estimation the optim procedure of $\mathrm{R}$ environment was utilized. In first two columns we give also the geometric Brownian motion mode parameters. These are given by simple closed form formulas

$$
\hat{\mu}_{\mathrm{BS}}=\overline{\mathrm{r}}=\frac{1}{n} \sum_{\mathrm{i}=1}^{\mathrm{n}} \mathrm{r}_{1}, \mathrm{~s}_{\mathrm{BS}}=\sqrt{\frac{1}{n} \sum_{\mathrm{i}=1}^{\mathrm{n}}\left(\mathrm{r}_{1}-\overline{\mathrm{r}}\right)^{2}}
$$

Table 5. Maximum likelihood estimators for the geometric Brownian motion and the jump-diffusion model parameters based on the data from the period 15th of January 2012 - 30th of August 2012. Bold font indicates the model which better fits to the distribution of daily returns in the remaining period of the year 2012.

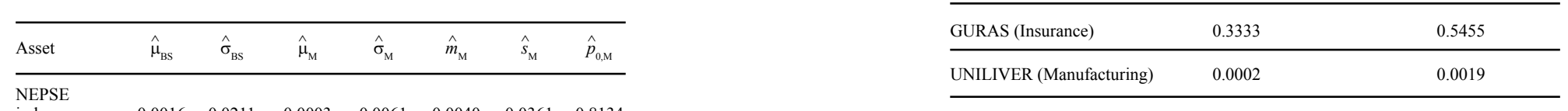

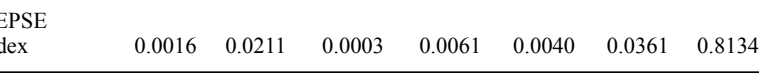

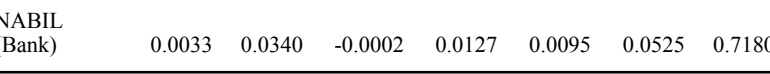

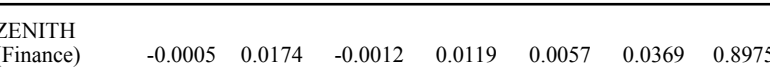
$\begin{array}{llllllllll}\substack{\text { OALTTEE } \\ \text { (totel) }} & 0.0026 & 0.0114 & 0.0017 & 0.0031 & 0.0000 & 0.0034 & 0.0000\end{array}$ IILIME \begin{tabular}{llll}
0.0049 & 0.0448 & 0.720 \\
\hline
\end{tabular} \begin{tabular}{lllllllll} 
(URAS & (nsurance) & 0.0021 & 0.0300 & 0.0016 & 0.0188 & 0.0021 & 0.0480 & 0.7920 \\
\hline
\end{tabular}

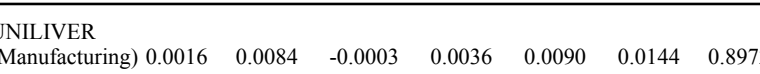

The reason for considering the period $15^{\text {th }}$ of January $2012-30^{\text {th }}$ of August 2012 instead of shorter period was such that the models obtained from much shorter periods fail to fit the distribution of the daily returns during the remaining period of the year 2012. The goodness of fit was tested with the Kolmogorov-Smirnov (K-S) test. (However, similar results are obtained e.g. for the period $15^{\text {th }}$ of January $2012-15^{\text {th }}$ of July 2012.) The results of K-S goodness of fit tests are shown in Table 6 .

The problems with the fit of the returns' distribution obtained from much shorter periods may be explained with the change of the market behavior due to considerable political unrests between April and June 2012 in Nepal. On May 27, Nepali Prime Minister Dr. Baburam Bhattarai dissolved the constitutional assembly without promulgating a new constitution. There were repeated market shutdowns and street protests organized by various groups and indigenous communities from April 2012 to June 2012 in Nepal, which caused the stock market highly volatile and unpredictable.

Table 6. Results of the Kolmogorov-Smirnov goodness of fit test of the models obtained applied to the data from the period $1^{\text {st }}$ of September 2012 $29^{\text {th }}$ of November 2012

\begin{tabular}{lcc}
\hline Asset & $\begin{array}{c}\text { The Geometric Brownian } \\
\text { motitin model K-s } \\
\text { statistic's p-value }\end{array}$ & $\begin{array}{c}\text { Merton's jump--iffusion } \\
\text { model K- } \\
\text { statistic's p-value }\end{array}$ \\
\hline NEPSE index & 0.0016 & 0.0940 \\
\hline NABLL (Bank) & 0.0051 & 0.5755 \\
\hline ZENITH (Finance) & 0.0345 & 0.1312 \\
\hline SOALTEE (Hotel) & 0.0110 & $<0.0001$ \\
\hline CHLIME (Hydropower) & 0.0088 & 0.5743 \\
\hline GURAS (Insurance) & 0.3333 & 0.5455 \\
\hline UNILIVER (Manufacturing) & 0.0002 & 0.0019 \\
\hline
\end{tabular}

\subsection{Three month VaR calculation.}

In Table 8 we present calculations of three month for both models as well as the realized losses i.e. the difference of the prices as of 30th of August and as of 29th of November 2012.

Table 7. Calculations of in both models and the realized losses

\begin{tabular}{|c|c|c|c|c|}
\hline Asset & $\begin{array}{c}\text { Price as of } \\
\text { 33th of } \\
\text { August } 2012\end{array}$ & 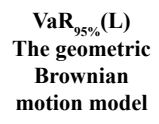 & 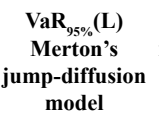 & $\begin{array}{l}\text { realized loss } \\
\text { (gain) }\end{array}$ \\
\hline NEPSE index & 405.82 & 337.85 & 179.62 & $(83.16)$ \\
\hline NABIL (Bank) & 1437 & 1353.10 & 992.12 & (23) \\
\hline ZENITH (Finance) & 95 & 75.27 & 68.01 & (9) \\
\hline SOALTEE (Hotel) & 248 & 143.93 & 55.53 & (75) \\
\hline CHILIME (Hydro) & 1070 & 975.04 & 543.15 & (48) \\
\hline GURAS (Insurance) & 132 & 121.73 & 110.43 & (15) \\
\hline $\begin{array}{l}\text { IIIVER } \\
\text { Inufacturi }\end{array}$ & 7938.60 & 3831.77 & 2211.34 & 342.27 \\
\hline
\end{tabular}

Analysing the Nepali Stock Market with Stochastic Models

Conclusions

The findings of this article indicate that Nepali stock market in 2012 was highly unstable, which made impossible to model the evolution of stocks prices at the Nepali Stock Exchange with the geometric Brownian motion model. The only representative of the Nepal capital market, which could be modelled with this model was a hotel company (SOALTEE). Though the VR test generally supports the random walk hypothesis (except for small holding periods, $\mathrm{k}=2,7)$ for all companies except a manufacturing company (UNILEVER), the nature of the price changes is too volatile to be captured by the geometric Brownian motion model.

Merton's jump-diffusion model, calibrated to the data from the period 15th of January 2012 - 30th of August 2012 gives much better fit to the distribution of daily returns in the remaining period of the year 2012 for majority of companies considered (banking, financial, hydropower, and insurance companies) This finding is different from the findings of the similar study conducted for the Polish capital market, Łochowski (2012), where both - the gBm and the Merton model were applied to selected WIG20 (Warsaw Stock Index 20) companies in the year 2011. In the year 2011, especially in it second half, financial markets used to react strongly to the signs of the deepening Eurozone crisis an stock prices behaved in very volatile way, but still, the simpler geometric Brownian motion mode outperformed the modeling capabilities of the jump-diffusion model in the period considered.

Additional incentive to apply Merton's model to the Nepali stocks is more reliable calculation of the Value at Risk measure. The 95\% VaR calculated with the Merton model is much smaller than the similar measure calculated with the use of the $\mathrm{gBm}$ model. For all companies except the hotel company, the three month $95 \%$ VaR estimate given by the $\mathrm{gBm}$ model is almost equal the actual price, which would indicate that with probability equal $5 \%$ the value of these shares would drop to the almost zero level within a three month period. 


\section{References}

Bhatta, G. P. (2010), Does NepaliStock Market Follow Random Walk?, SEBON Journal, 4, 18-58.

Black, F., Scholes, M. (1973), The pricing options and corporate liabilities, Journal of Political Economy, 81(3), 637-654.

Cuthbertson, B. (1996), Quantitative Financial Economics, John Wiely \& Sons, New York.

G.C., Surya Bahadur (2010), Weak Form of Market Efficiency: Evidence from Nepali Stock Market, Available at http://dx.doi.org/10.2139/ $\underline{\operatorname{ssm} .1568694 .}$

G.C., Surya Bahadur (2008), Volatility Analysis of Nepali Stock market, The journal of Nepali Business Studies, 5(1), 76-84.

Gurung, J.B. (2004), Growth and performance of securities Market in Nepal, The Journal of Nepali Business Studies, 1(1), 85-92.

Joshi, N., K.C., Fatta Bahadur (2005), The Nepali Stock Market: Efficiency and Calendar Anomalies: Nepal Rastra Bank, 17, 43-87.

Kadaria, S. (2011), Market reaction to tangible and intangible information: A case of Nepal, Banking Journal, 2(1), 41-64.

Kendall, M. G. (1953),T he Analysis of Economic Time-Series, Part I. Prices, Joturnal of the Royal Statistical Society, 116(1), 11-34.

Lo, A.W., Mackinlay, A.C. (1988), Stock Market Prices Do Not Follow Random Walks: Evidence from a Simple Specification Test, Review of Fincancial Studies, 1(1), 41-66.
Lock, D. B. (2007), The Taiwan Stock Market Does Follow a Random Walk, Economics Bulletin, 7(3), 1-8.

Lochowski, R. M. (2012), The Black-Scholes vs. the Merton jump-diffusion model applied to selected WIG20 companies in the year 2011 , accepted to the monograph Zastosowanie Metod Ilosiciowych w Zarzadzaniu Ryzykiem w Dzialalności Inwestycyjnej, PTE Katowice 2013.

Merton, R C. (1976), Option pricing with discontinuous returns, Bell Journal of Financial Economics, 3(1-2), 145-166.

Neftci, N.S. (1998), An Introduction to the Mathematics of financial Derivatives ( $2^{\text {nd }}$ ed.), Academic Press.

Pradhan, R. S., Balampaki, S.B. (2004), Fundamentals of stock returns in Nepal, SEBON Journal, 1, 8-24.

Pradhan, R S., KC, S. (2010), Efficient Market Hypothesis and Behaviour of Share Prices: The Nepali Evidence, SEBONJournal, 4,104-117.

Wilmott, P. (1997), Derivatives: The Theory and Practice of Financial Engineering ( $2^{\text {nd }} \mathrm{ed}$.), John Wiley \& Sons Ltd.

Wilmott, P., Howison S. and Dewynne, J. (1997), The Mathematics of financial Derivatives: a Student Introduction ( $2^{\text {nd }}$ ed.), Cambridge University Press. 